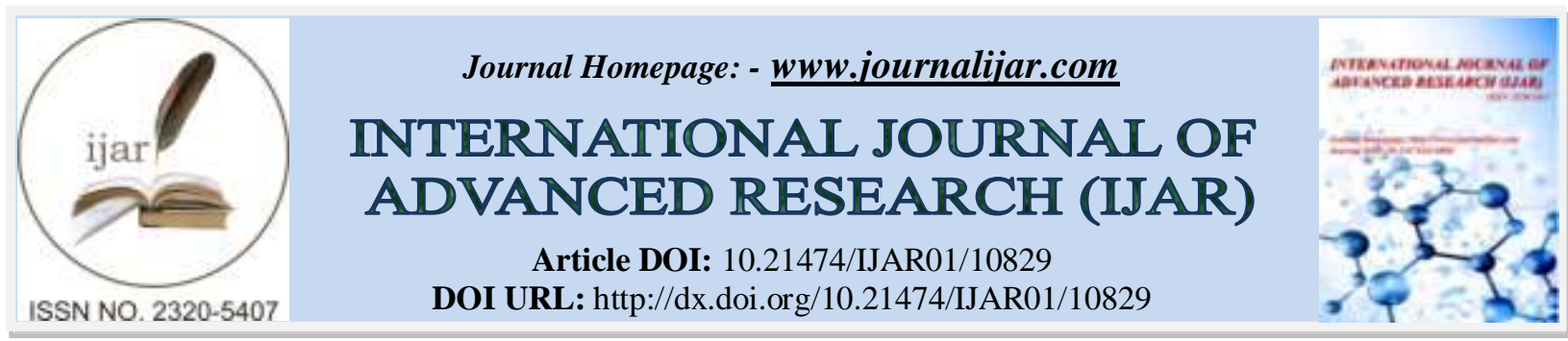

RESEARCH ARTICLE

\title{
A STUDY OF HISTOPATHOLOGICAL SPECTRUM OF BENIGN BREAST DISEASES - A TWO YEAR RETROSPECTIVE ANALYSIS
}

\author{
Ameet Kaur ${ }^{1}$, Bhavneet Kour ${ }^{2}$ and Subhash Bhardwaj ${ }^{3}$ \\ 1. Assistant Professor, Department of Pathology, Govt. Medical College, Jammu. \\ 2. Senior Resident, Department of Pathology, Govt. Medical College, Jammu. \\ 3. Professor and Head, Department of Pathology, Govt. Medical College, Jammu.
}

\section{Manuscript Info}

\section{Manuscript History}

Received: 14 February 2020

Final Accepted: 16 March 2020

Published: April 2020

Key words:-

Benign Breast Diseases, Fibroadenoma,

Fibrocystic Disease

\begin{abstract}
Background: Study of patterns of benign breast diseases is a challenge due to the variations in occurrence and presentation in the different age groups. Women with benign breast diseases are at a high risk of developing breast cancer. Early presentation and prompt diagnosis is essential to relieve the anxiety of non neoplastic conditions. Analysis of patterns and frequency provide a valuable guideline for the clinical diagnosis of these lesions.

Materials and Methods: This study was undertaken in the department of Pathology, GMC, Jammu. The purpose of the study was to analyse the spectrum of benign breast diseases to understand their prevalence and age wise comparison. Data of 70 cases of benign breast diseases during a time span of two years (2017-2019) was obtained retrospectively. All breast tissue samples were processed by the standard procedure and formalin fixed paraffin embedded tissue sections were studied and analysed.

Results: Non malignant breast lesions include a variety of inflammatory lesions, benign tumours and tumour like conditions. Fibroadenoma(58.6\%) is found to be the commonest followed by Fibrocystic disease in $8(11.4 \%)$ cases. Most of the cases of benign breast diseases were in the age group of 21-30years (33) followed by 15 cases in the age group of 31-40years.

Conclusion: Benign breast diseases constitute a heterogenous group of disorders which is more frequent than malignant ones and is one of the most important cause of breast problems in females. Histopathological evaluation becomes necessary for such cases and plays an important role in their final diagnosis.
\end{abstract}

Copy Right, IJAR, 2020,. All rights reserved.

\section{Introduction:-}

Breast tissue in females is under the effect of various hormones and is subjected to constant physiological variations throughout the reproductive life and beyond. ${ }^{(1)}$

The term 'Benign breast disease' is made up of a heterogenous group of diseases that have varied symptoms or may be detected as incidental microscopic finding. The benign lesions can originate from the different kinds of cells and 
can be inflammatory or proliferative. Benign breast disease is usually common in younger population and the incidence rises during the second decade of life and peaks in the fourth and the fifth decade. ${ }^{(2)}$

Currently the female breast is one of the most commonly biopsied tissue because of myriads of diseases and lesions that arise from it. ${ }^{(3)}$ Benign breast diseases forms majority, accounting for $90 \%$ of breast lesions worldwide. ${ }^{(4)}$ Majority of these lesions present as palpable mass, nipple discharge and pain. These features constitute anxiety among the women and their relatives due to the increased awareness of incidence of breast cancer worldwide. Studies have shown that there is a five times increased risk of breast cancer in patients that have some incidence of the benign breast lesions. ${ }^{(5)}$

Breast lesions have become one of the leading cause of death among women worldwide. ${ }^{(6)}$ In India, breast cancer is the second most common cancer after cervical cancer. ${ }^{(7)}$

Advances in imaging techniques along with increased use of FNAC have greatly aided the pre-operative evaluation of breast lesions. In majority of cases, the differentiation between benign and malignant lesions still lie on histopathological examination. The importance of benign lesions lie in their ability to mimic cancers, and not all the benign lesions are completely free of risks. Treatment of benign breast diseases is preservation of breast tissue as far as possible in contrast to traumatizing mutilating surgeries in breast cancer. ${ }^{(2)}$ In other words, in order to prevent unnecessary loss of breast, accurate diagnosis of non malignant lesions is of utmost importance.

The main purpose of this study is to know about the histopathological spectrum of various non malignant breast lesions and their frequency of occurrence. Benign breast diseases are common among young females. ${ }^{(2)}$ Distinguishing the heterogenous form by histopathological examination is very important for prognostic prediction. ${ }^{(8)}$

\section{Materials and Methods:-}

The present study is a retrospective study done in the Department of Pathology, GMC, Jammu over a period of 2 years from Jan 2017 to Dec 2019. Tissue for Haematoxylin and Eosin sections was fixed in 10\% Formalin and subjected to the routine paraffin embedding, processing and stained with Haematoxylin and Eosin. Corresponding slides were retrieved and where such slides could not be recovered, the stored paraffin embedded tissue blocks in the archives were recovered and new slides were prepared with routine standard procedure.

The cases were analysed on the basis of age and histological lesions. All the data obtained was tabulated and analysed.

\section{Results:-}

A total of 70 cases of benign breast disease were analysed. Most commonly seen Benign breast lesion was Fibroadenoma accounting for $41(58.60 \%)$ cases followed by Fibrocystic disease, seen in 8(11.42\%) cases.[Table1]

Age wise distribution pattern reveals most of the cases of benign breast diseases in the age group of 21-30years (33) followed by 15 cases in the age group of 31-40years.[Table 2]

Table 2:- Histopathological distribution pattern in benign breast diseases.

\begin{tabular}{|l|l|l|}
\hline BENIGN BREAST DISEASES & TOTAL (70) & PERCENTAGE \\
\hline Fibroadenoma & 41 & $58.60 \%$ \\
\hline Benign Phylloides & 2 & $2.85 \%$ \\
\hline Gynaecomastia & 3 & $4.28 \%$ \\
\hline Lactating Adenoma & 4 & $5.71 \%$ \\
\hline Fibrocystic Disease & 8 & $11.42 \%$ \\
\hline Duct Ectasia & 2 & $2.85 \%$ \\
\hline Granulomatous Mastitis & 1 & $1.42 \%$ \\
\hline Breast Abscess & 6 & $8.60 \%$ \\
\hline Galactocele & 1 & $1.42 \%$ \\
\hline Lipoma & 2 & $2.85 \%$ \\
\hline Total & 70 & $100 \%$ \\
\hline
\end{tabular}


Table 2:- Age wise distribution of benign breast diseases $(\mathrm{n}=70)$.

\begin{tabular}{|l|l|l|l|l|l|l|l|}
\hline BENIGN BREAST DISEASES & $\mathbf{1 1 - 2 0}$ Yrs & $\mathbf{2 1 - 3 0}$ Yrs & $\mathbf{3 1 - 4 0}$ Yrs & $\mathbf{4 1 - 5 0}$ Yrs & $\mathbf{5 1 - 6 0}$ Yrs & $\begin{array}{l}>60 \\
\text { Yrs }\end{array}$ & TOTAL \\
\hline Fibroadenoma & 10 & 22 & 6 & 2 & 1 & - & 41 \\
\hline Benign Phylloides & - & & & 2 & - & - & 2 \\
\hline Gynaecomastia & - & 2 & - & 1 & - & - & 3 \\
\hline Lactating Adenoma & - & 4 & - & - & - & - & 4 \\
\hline Fibrocystic Disease & - & 2 & 5 & 1 & - & - & 8 \\
\hline Duct Ectasia & - & - & 2 & - & - & - & 2 \\
\hline Granulomatous Mastitis & - & - & 1 & - & - & - & 1 \\
\hline Breast Abscess & - & 3 & 1 & 1 & 1 & - & 6 \\
\hline Galactocele & - & 1 & - & - & - & - & 1 \\
\hline Lipoma & - & 1 & - & 1 & - & - & 2 \\
\hline
\end{tabular}

Fibroadenoma accounted for $41(58.60 \%)$ cases of all benign lesions, majority of cases were seen in 21-30years (53.65\%) followed by $10(24.39 \%)$ cases in 11-20years. Histologically, they were characterised by overgrowth of both fibrous stroma and of epithelial elements i.e. ducts and lobules in differing proportions and cyst formation.

Benign phylloides tumour was seen in $2(2.85 \%)$ cases of all benign lesions in our study. Majority were seen in the age group of 41-50years. 3 (4.28\%) cases were histopathologically diagnosed as Gynaecomastia. Most were in the second decade. Grossly, masses were well circumscribed and firm. Microscopically, ducts showed variable degree of epithelial hyperplasia, surrounded by prominent proliferating stroma.

Lactating adenoma was found in 4(5.71\%) cases. All were seen in 21-30years. Grossly, it measured 3cms and on microscopy, lesion showed numerous closely packed uniform small tubules, lined by benign epithelium with very scant stroma.

Duct ectasia was also found in 2(2.85\%) cases. Microscopically, lesions were characterized by foamy macrophages surrounding dilated ducts. 1 case $(1.42 \%)$ of Granulomatous mastitis was found which microscopically showed non caseating granulomas.

2 cases $(2.85 \%)$ of Lipoma were noted in 22 and 45year old females. 6 cases of Breast abscess and 1 case of Galactocele were noted.

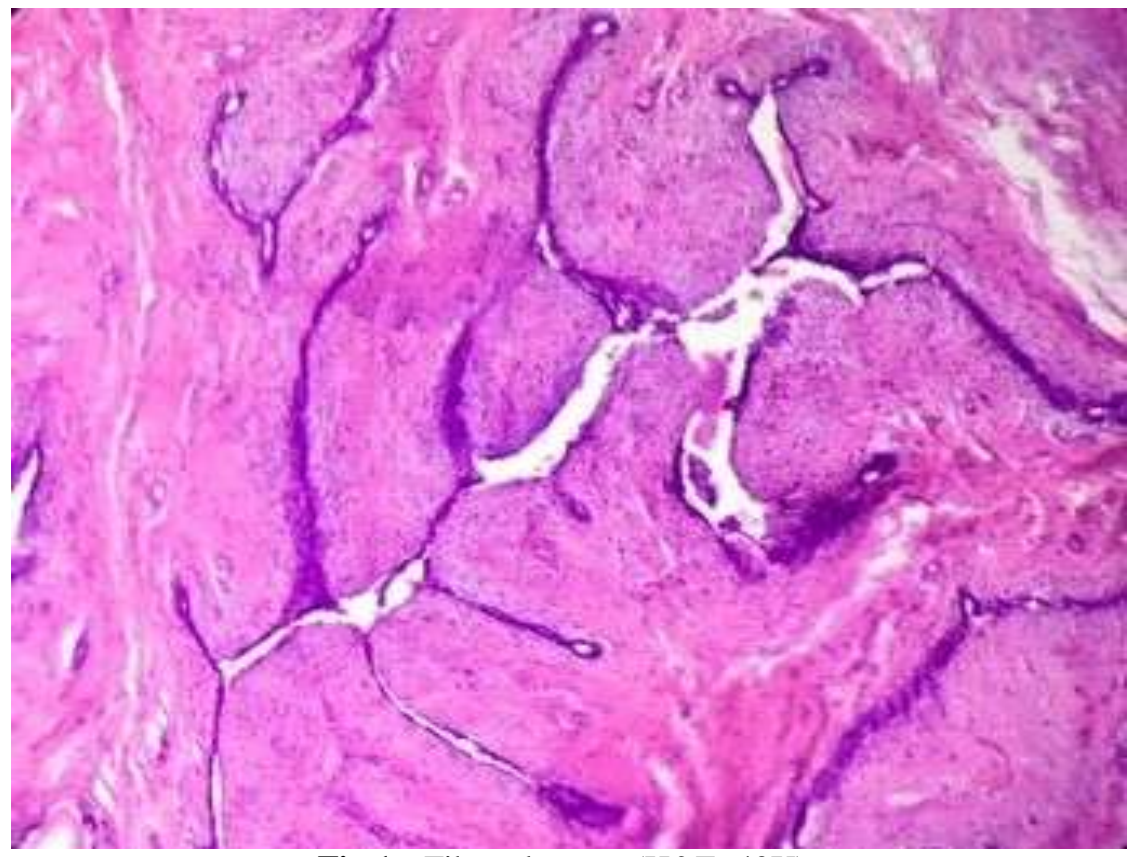

Fig 1:- Fibroadenoma (H\&E, 40X). 


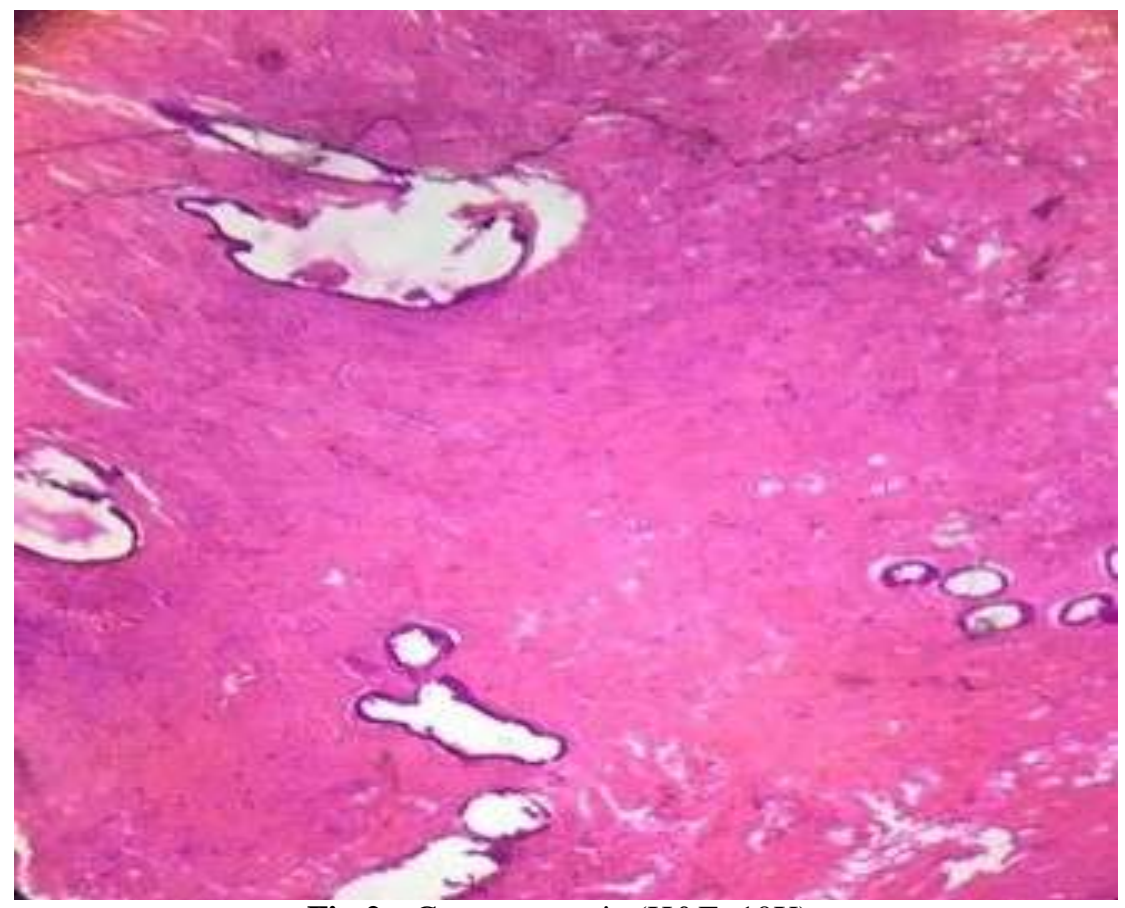

Fig 2:- Gynaecomastia (H\&E, 10X).

\section{Discussion:-}

Breast tissue in females is under the effect of various hormones and is subjected to the constant physiological variations throughout the reproductive life and beyond. This leads to varied clinical manifestations and diseases. ${ }^{(1)}$ Benign breast lesions demand attention because of their prevalence, their impact on women's life and due to the cancerous potential of some histological types. ${ }^{(8)}$ Since a majority of benign lesions are not associated with an increased risk for subsequent breast cancer unnecessary surgical procedure can be avoided in such lesions. ${ }^{(9)}$

Fibroadenoma (58.60\%) was the most common lesion seen in our study. The cause of high frequency among our females is not clear but racial predisposition could be a factor. It is usually a disease of early reproductive life. It is frequently multiple and bilateral. Young females present with palpable mass and older women with mammographic density and calcification. Our findings were consistent with Hatim et al. ${ }^{(10)}$ and Dayanand et al. ${ }^{(11)}$ Dayanand et al. ${ }^{(11)}$ reported $41.9 \%$ of fibroadenoma between 21 to 30 years followed by $30.5 \%$ in 11 to 20 years. Higher incidence in second and third decade was also reported by Hatim et al. ${ }^{(10)}$

Benign Phylloides tumour accounted for $2.85 \%$ of all benign lesions. Study by Hatim et al. reported an incidence of $3.4 \%$ of benign Phylloides. We noticed that it was more common in fifth decade of life.

Gynaecomastia constituted 3 cases (4.28\%) of all benign lesions in male patients. Hatim et al. reported an incidence of $4.3 \%$.

Lactational adenoma was mostly common during the reproductive period and are usually seen during $21-30$ years. Our present study includes 4 cases and findings are comparable with Pudale et al. ${ }^{(12)}$ We reported 2 cases of Lipoma in breast in a 22 year and a 45 years old female. Pudale et al. also reported 2 cases of Lipoma with a mean age of 45 years. Incidence of our study also corelated with study of Mudhalkar et al. ${ }^{(13)}$

Fibrocystic disease was the next common lesion accounting for $11.42 \%$ of all benign lesions in our study. Fibrocystic change accounted for $16.2 \%$ of cases of Dayanand et al. ${ }^{(11)}$ Fibrocystic lesions are generally treated medically, respond well to hormonal treatment and less frequently require excision. ${ }^{(14)}$ Majority of our patients with Fibrocystic disease were in the third to fourth decade of life. Sangma et al. ${ }^{(9)}$ reported an incidence of $19.7 \%$ of Fibrocystic disease with a high incidence in third to fourth decade. Fibrocystic disease of breast clinically presents with lumpy bumpy breast on palpation. It includes three components as cysts, fibrosis and adenosis. The cyst lining 
may be flattened or shows apocrine metaplasia and epithelial hyperplasia. Epithelial hyperplasia whether typical or atypical puts the patient in a higher risk of cancer development. ${ }^{(8) .}$

Duct ectasia is a condition in which there is an obstruction and associated inflammation of the lactiferous duct. The main importance of this lesion is that it is usually considered as a precursor for malignancy. Mammary duct ectasia can mimic breast cancer as the disorder presents with nipple retraction, pain, swelling and bloody nipple discharge. ${ }^{(8)}$ Duct ectasia was seen in 2 cases $(2.85 \%)$ consistent with the incidence of $2.77 \%$ reported by Rasheed et al. ${ }^{(15)}$

Granulomatous inflammatory changes in the breast can be related to specific infectious agents such as mycobacterium tuberculosis, foreign material such as silicone or suture material, trauma or systemic autoimmune disease. ${ }^{(1)}$ We had 1 case of Granulomatous mastitis $(1.42 \%)$. Hatim et al. ${ }^{(10)}$ reported an incidence of $2.4 \%$

Majority of the breast abscess cases were in the age group of 21-30 years(50\%) reflecting the association of this lesion with pregnancy and lactation. It appears that the frequency of breast abscess is not reflective of the clinical incidence of the disease. This may be attributed to the fact that most breast abscesses are drained and only a minority is biopsied. ${ }^{(1)}$

One case of Galactocele was seen in 25 years lactating female in our study (1.42\%). This was in accordance to the studies done by Bagale et al. ${ }^{(16)}$ as $1.02 \%$ and Khanna et al. ${ }^{(17)}$ as $1.20 \%$

\section{Conclusion:-}

Benign breast diseases constitute a heterogenous group of disorder which is more frequent than malignant ones and is one of the most important cause of breast problems in females. The spectrum of benign breast diseases in our study does not appear to differ much from the other studies with Fibroadenoma being the most common benign breast disease followed by Fibrocystic disease. Histopathological evaluation becomes necessary for such cases and plays a important role in the final diagnosis and becomes helpful to the surgeons for making the decision of further operative management of the patient. Benign breast diseases constitute a source of morbidity and mortality for the women of all age groups. Therefore, adequate health campaign awareness, screening and follow up of all benign breast lesions may help to reduce the burden of these lesions. It is advisable that all the cases of breast lesions should be carefully evaluated to exclude the possibility of breast carcinoma.

\section{References:-}

1. Rahman MA, TalukderSI;Benign Breast Diseases-A Histopathological study;Dinajpur Med Col J 2016 Jul;9(2):187-193.

2. Koorapati Ramesh, KishanBookya; A study on clinical and pathological correlation of benign breast lesions:International Surgery Journal:2017 Aug 4(8):2700-2705.

3. Forae G D, Nwachokor F N, IgbeAP,OdokurnaEI,Ijomone EA. Benign breast diseases in Warri Southern Nigeria. A spectrum of histopathological analysis. Ann Nigerian Med 2014;8:28-31.

4. Murollo Ortiz B,Botello Hernandez D,Ramirez Mateos C,Reynaga Garcia FJ.Benign breast diseases:Clinical,radiological and pathological correlation;GIlinecolObstetMex 2002;70:613-8.

5. Olu-Eddo AN, Igiagbe EE.Benign breast leisions in an African population. A 25-year histopathological review of 1864 cases. Niger Med J 2011;52:211-6.

6. Reddy M, Raghu K. Histopathological spectrum of neoplastic and non neoplastic breast leision-a two year study. Int J Sci Stud 2017; 4(11):158-162.

7. Dhiraj B Nikumbh. Histopathological spectrum of unusual breast lesions-a seven year retrospective review. Indian Journal of Pathology and Oncology 2016;3(3):456-462.

8. Vilasini Patil, Archana Khandelwal, Kanchanmala G, Ghorpade. Histopathological Spectrum of Benign Breast Lesions, J Res Med Dent Sci,2017, 5(4):9-14, DOI;10.24896/jrmds. 2017543.

9. Sangma MBM, Panda K, Dasiah S. Aclinico-pathological study on benign breast Diseases. J Clin Diagn Res 2013;7(3):503-6.

10. Hatim KS, Laxmikant NS, Mulla T. Patterns and prevalence of benign breast disease in Western India Int J Res Med Sci 2017;5(2):684-688.

11. Dayanand V,Shashidhar HB, Sandya M, Ashwani NS, Bharathi M. Spectrum of breast neoplasms in females:a 10 years Histopathological review in a tertiary care hospital. Int J Sci .stud. 2015;3(2):79-84. 
12. Pudale S, TonapeSD.A histopathological study of non malignant breast lesions.Int $\mathrm{J}$ Res Med Sci 2015;3(10):2672-6.

13. Mudholkar VG, KawadeSB,Mashal SN. Histopathological study of neoplastic lesions of breast, Indian Medical Gazette.2012;353-60.

14. Jyoti Sharma, Hem Chander Pandey; A Review of spectrum of breast lesions in a Tertiary Care Centre; A Retrospective study. JMSCR Vol 07 Issue 01 Jan 2019:128-131.

15. Rasheed A,SharmaS,Mohsin-ul-Rasool,BashirS,HafizA,Bashir N. A three year study of breast leisions in women aged 15-70years in a tertiary care hospital. Sch. J. App. Med. Sci. 2014;2(1B):166-8.

16. Bagale P, Dravid N V ,Bagale S, Ahire N.Clinicopathological study of Benign Breast Diseases. International Journal of Health Sciences and Research. 2013;3(2).

17. Khanna S, Arya N C,Khanna N N.Spectrum of benign breast disease. Indian J of Surgery 1988;50:1697. 